\title{
Spectrophotometric Determination of Malathion in Environmental Samples
}

\author{
N. V. S. VENUGOPAL ${ }^{*}$, B. SUMALATHA AND SYEDABANO \\ Department of Chemistry,G.I.T,GITAM University \\ Rushikonda,Vsakhapatnam-530045.A.P,India \\ venu7000@gmail.com
}

Received 28 July 2011; Accepted 4 October 2011

\begin{abstract}
A simple, rapid, sensitive, and precise spectrophotometric method for the determination of Malathion is described. The method is based on the decomposition of Malathion in the presence of alcoholic $\mathrm{KOH}$. Dimethyldithiophosphate produced is made to react with Ammonium meta vanadate in Nitric acid with the formation of blue color. Acid degradation of too slow to be important under environmental reaction conditions. However, alkaline degradation is too fast to be a pathway in environmental condition. The products of alkaline degradation are temperature dependant. The absorbance maximum was observed at $760 \mathrm{~nm}$. The Beers law is obeyed up to $11 \mathrm{ppm}$. Interference study was carried for other pesticides.
\end{abstract}

Keywords: Spectrophotometry, Malathion, Ammonium meta vanadate.

\section{Introduction}

The use of pesticides helped to significantly reduce crop losses and to improve the yield of crops such as corn, maize, vegetables, potatoes, and cotton. Worldwide the use of pesticides increased tremendously since the 1960s. Notwithstanding the beneficial effects of pesticides, their adverse effects on environmental quality and human health have been well documented worldwide and constitute a major issue that gives rise to concerns at local, regional, national, and global scales. Residues of pesticides contaminate soils and water, persist in the crops, enter the food chain and finally are ingested by humans with foodstuffs and water. Furthermore, pesticides can be held responsible for contributing to biodiversity losses and deterioration of natural habitats.

Malathion ( $S$-1,2-bis(ethoxycarbonyl)ethyl-O,O-dimethyl-phosphorodithioate) is a widely used organophosphorus pesticide for the control of household and poultry pests, pests in vegetables, field crops, fruits, nuts, tea, coconut, cashew nuts, stored grains, and domestic animals. 


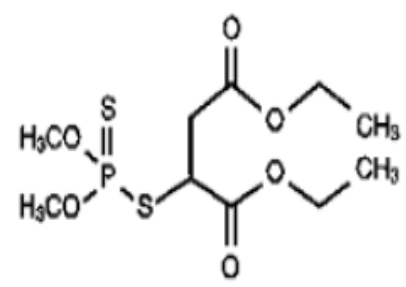

Figure 1. Structure of malathion.

It has been the subject of many studies relating to its persistence and fate in soil, plants, and grains ${ }^{1}$. A possible concern is that malathion being used in an outdoor environment, could enter a house or other building; however, studies by the EPA have conservatively estimated that possible exposure by this route is well below the toxic dose of malathion. Regardless of this fact, in jurisdictions which spray malathion for pest control, it is often recommended to keep windows closed and air conditioners turned off while spraying is taking place, in an attempt to minimize entry of malathion into the closed environment of residential homes. This pesticide can be determined by different methods.

Many procedures are reported in literature for determining Malathion in pure or formulated methods such as colorimetry ${ }^{2-6}$, Gas chromatography ${ }^{7-9}$, Infrared spectrophotometry ${ }^{10}$, and mass spectrometry ${ }^{11}$ have been used. For example, it can be hydrolyzed quantitatively in alkaline media to dimethyldithiophosphate (DMDTP) which in the presence of $\mathrm{Cu}(\mathrm{II})$, $\mathrm{Bi}(\mathrm{III})$, and $\mathrm{Mo}(\mathrm{IV})$ or Methylene Blue forms complexes that can be extracted in organic solvents and measured spectrophotometrically ${ }^{12-15}$. To enhance the sensitivity, the DMDTP has been extracted with Rhodamine $6 \mathrm{G}$ as an ion pair into toluene and measured fluorometrically. ${ }^{16}$ Atomic absorption spectrometry has also been used for the indirect determination of malathion by formation and later extraction of the palladium chloridemalathion complex ${ }^{17}$. An environmentally friendly methodology has been developed for quality control analysis of emulsifiable concentrate pesticide formulations containing Malathion as active ingredient, using flow injection analysis (FIA)-Fourier transform infrared (FTIR) spectrometry ${ }^{18}$.

The spectrophotometric method developed by NORRIS et al. ${ }^{19}$ for the determination of malathion has been extensively employed and has been recommended as suitable for malathion residue analysis by the Malathion Panel, set up jointly by the Scientific SubCommittee of the Inter -Departmental Advisory Committee on Poisonous Substances LJsed in Agriculture $2^{\text {nd }}$ Food Storage, the Analytical methods committee of the Society or Analytical Chemistry and Association of British Manufacturers of Agricultural Chemicals ${ }^{20}$.

In addition, it is the recommended method of the US Association of official Analytical Chemists $^{21}$. Reddy et al. ${ }^{22}$ determined malathion by using gention violet. Ayman ${ }^{23}$ described a method based on oxidation of malathion with a slight excess of $\mathrm{N}$-bromosuccinamide and determined the unreacted with amaranth dye. Due to its wide use and toxicity, several, spectrophotometric methods ${ }^{24}$. Most spectrophotometric procedures involve the determination of organophosphorus insecticides by total phosphorus measurement. 
The proposed method has been successfully applied for the determination of malathion in water and vegetables. The vegetable samples collected from various places near sabbavaram area, Visakhapatnam District, Andhra Pradesh, India.

\section{Experimental}

A Jasco (Model Uvidec-610 UV-VIS Spectrophotometry with $1 \mathrm{~cm}$ matched quartz cuvettes was used for all absorbance measurements. Standard Solution: 1000-ppm solution of Malathion in acetone was prepared by dissolving $0.1 \mathrm{~g}$ of known Malathion standard in $100 \mathrm{~mL}$ acetone. Stock Solution: - Stock solutions were prepared by dissolving $5 \mathrm{mg}$ of malathion in $50 \mathrm{~mL}$ of water. All other chemicals were of analytical glade and provided from Merck.

\section{Procedure}

\section{Method I}

An aliquot of the malathion stock solution and $1 \mathrm{ml}$ potassiumhydroxide and $2 \mathrm{~mL}$ of ethylalcohol were introduced into a $25 \mathrm{~mL}$ standard flask and made up to volume with niric acid and with water. The resultant mixture was heated at $50-70^{\circ} \mathrm{C}$. The resulting absorbance of the blue color was measured at $760 \mathrm{~nm}$ employing all reagents. The experiments were repeated with different volumes of standard malathion solution and a calibration curves were prepared the color reaction obeys Beer's law from 0.01 to $11 \mathrm{mg} / 10 \mathrm{~mL}$ of malathion.

\section{Method II}

Water samples $(5 \mathrm{~mL}), 5 \mathrm{~g}$ of finely ground vegetable samples $(5 \mathrm{~g})$ were spiked with known amount of the working standard solution of malathion. Aliquots of the washed extracts of endosulfan were evaporated off under suction. To the residue, $5 \mathrm{~mL}$ of acid reagent and $1 \mathrm{~mL}$ of alcoholic potassium hydroxide solutions were added. $5 \mathrm{ml}$ of ammonium meta vanadate was added and analyzed by the proposed method. Suitable volume of aliquot was analyzed according to the proposed and reference method. The results are tabulated in tables 1 and 2 .

Table 1. Determination of malathion in water and vegetables.

\begin{tabular}{cllc}
\hline S.NO & Samples & \multicolumn{2}{c}{$\begin{array}{c}\text { Amount of Malathion }(\mu \mathrm{g} / \mathrm{mL})^{* *} \\
\text { Reference } \text { method }^{25}\end{array}$} \\
\hline 1 & water & $1.63 \pm 0.01$ & $1.61 \pm 0.01$ \\
2 & Vegetables & & $5.06 \pm 0.02$ \\
& Cauliflower & $5.12 \pm 0.02$ & $6.0 \pm 0.05$ \\
& Potato & $6.1 \pm 0.03$ & $11.23 \pm 0.01$ \\
\hline & Spinach & $11.0 \pm 0.05$ & \\
\hline \multicolumn{3}{c}{${ }^{* *}$ mean \pm standard deviation $(n=5)}$. \\
\hline
\end{tabular}

Table 2. Optical characteristics and precision data.

\begin{tabular}{cc}
\hline$\lambda_{\max }, \mathrm{nm}$ & $760 \mathrm{~nm}$ \\
\hline Color & blue \\
Beer's law range & $0.5-11 \mu \mathrm{g} / \mathrm{mL}$ \\
Detection limit & $0.13 \mu \mathrm{g} / \mathrm{mL}$ \\
\hline
\end{tabular}




\section{Results and Discussion}

Spectral Characteristics

Acid degradation of too slow to be important under environmental reaction conditions. However, alkaline degradation is too fast to be a pathway in environmental condition. The products of alkaline degradation are temperature dependant.

The absorption spectra of the reaction product of malathion with ammonium meta vanadate shown in Figure 2 with maximum absorption at $760 \mathrm{~nm}$. A temperature range of $50-70^{\circ} \mathrm{C}$ is selected for the reaction. Beer's law was obeyed and the linearity graph is shown in Figure 3 in the concentration range of $0-01-11 \mathrm{mg} / 10 \mathrm{~mL}$ of malathion.

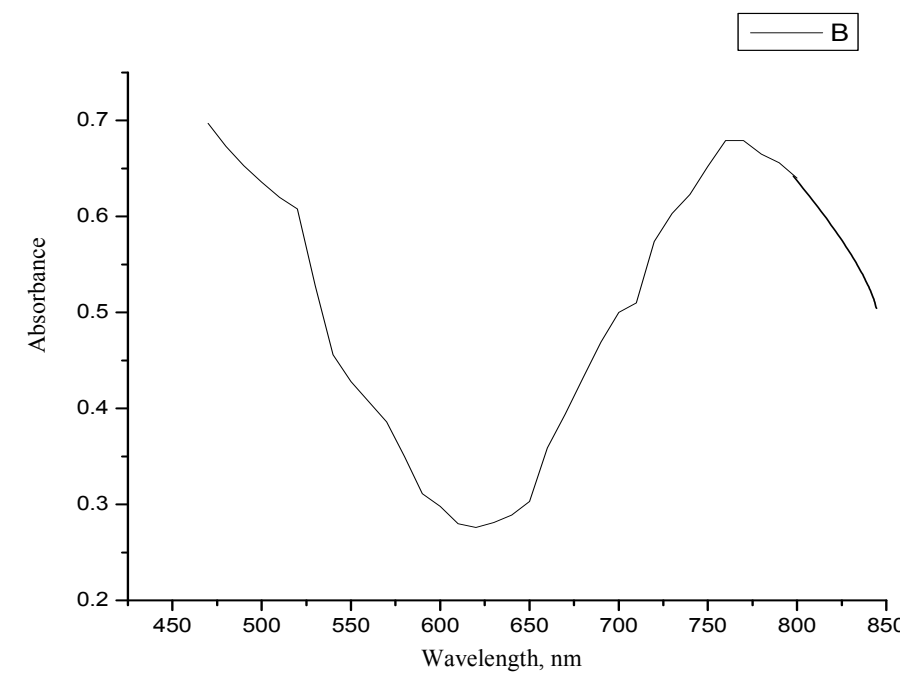

Figure 2. Absorption maximum of malathion with ammonium metavanadate.

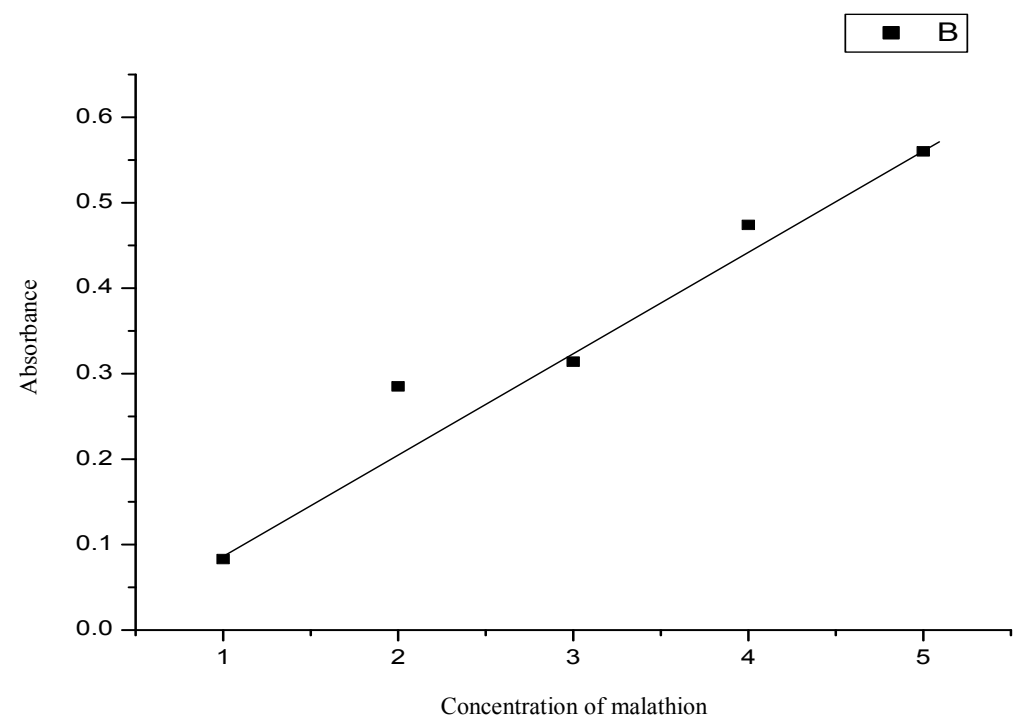

Figure 3. Absorbance versus concentration graph of malathion. 


\section{Effect of Color Producing Reagent}

The rate of formation of complex in solution is generally rapid (45 seconds in color reaction) changes in spectrum or color are associated with a transfer/interchange of electrons when such molecules undergo properly oriented collisions. The absorbance of the developed color was stable for more than three hours.

\section{Sensitivity}

The results for the determination of malathion are shown in tables 1 and 2 which reveal the sensitivity, validity and repeatability of the method. The method is also reasonably precise and accurate, as the amount taken from various samples is known and the amount found by the above procedure does not exceed the relative standard derivative of $0.74 \%$. The optimization has been done at lower analyte concentration. The method has been applied for the determination of malathion in various water and vegetable samples. The various samples were collected from sabbavaram areas in Visakhapatnam District, Andhra Pradesh, India.The various vegetables collected are cauliflower, potato, spinach, etc. The proposed method is simple, selective, sensitive, and rapid, offers the advantage of high sensitivity.

\section{Conclusion}

The spectrophotometric method for the determination of malathion is simple, reliable, sensitive and less time consuming. The color reaction is selective for malathion. The advantage of the present procedure is that it does not require many solvents, where as the HPCL procedures are long, tedious, and expensive, involving many reagents and solvents showing high RSD value.

\section{References}

1. Mensah G W K, Pestic Sci., 1987, 20, 161-166.

2. NorrisM V, Vail W A and Averell P R, J Agric Food Chem., 1954, 2, 570.

3. Upham S D, Ass J off Agric Chem., 1960, 43, 360.

4. Ware J H, ibid., 1961. 44, 608.

5. Ware J H, ibid., 1962, 45, 529.

6. Orloski E.J, J Ass off Agric Chem., 1964, 47, 248.

7. Boyd J E, "Analytical Methods for Pesticides and Plant Growth Regulators", Vol. VT, Academic press, New york, 1972, p. 418.

8. Malathion manula for Insecticide Formulators" compiled by Cyanamid International.1964

9. Dasciana Rodrigues, Chromatography Research Inernational, 2011, articleID 713256

10. Das G K, Thayumanavan B, Vacha S M, and Natu L K, Res Indust., 1973, 18, 100.

11. Wayne R S, J Ass Off Anal Chem., 1979, 62, 292.

12. Norris M V, Avail W and Averell P R, J Agric Food Chem., 1954, 2, 570-573.

13. Clark E R and Qazi I A, Analyst, 1979, 104, 1129-1134.

14. Venkatadri Naidu U,.Gangaiah T, Ramadevi P, Seshaiah K and Naidu G R K, Talanta, 1990, 37, 761-762.

15. Seshaiah K and Mowli P, Analyst, 1987, 112, 1189-1190.

16. Rama Mohan K, Ramesh A and Seshaiah K, Analyst, 2000, 125, 323-326.

17. Hernandez Mendez J, Jimenez and Lozano O, Microchem J., 1988, 38, 355-361.

18. Guillermo Quintas, Asuncion Morales Anal Chem Acta, 2004, V502(2), 213-220.

19. Norris M V, Vail W A and Averell P R, J Agric Pd Chem., 1954, 2, 570.

20. Malathion Panel, Analyst, 1960, 85, 915. 
862 N. V. S. VENUGOPAL et al.

21. Official Methods of Analysis of the Association of Official Analytical Chemists", Eleventh Edition, Association of Official Analytical Chemists, Washington, D. C., 1970.

22. Reddy K M and Suvardhan K, E-J Chem., 2005, 2(3), 187-192.

23. AymaA.Gouda and Alaas Amin, Chem Indust Chem, Eng., 2010, 16(1), 11-18.

24. Mathew S B Pillai A K and Gupta V K, Spectrochim Acta, 2007, (A)67, 1430.

25. Clark R and Quazi I A, Analyst, 1980, 105, 564-567. 


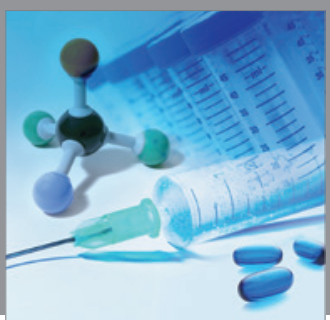

International Journal of

Medicinal Chemistry

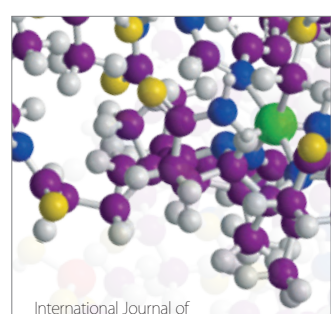

Carbohydrate Chemistry

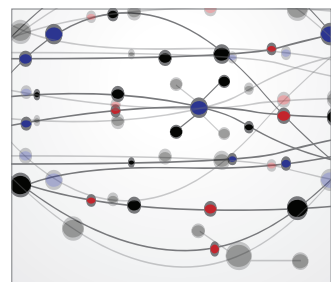

The Scientific World Journal
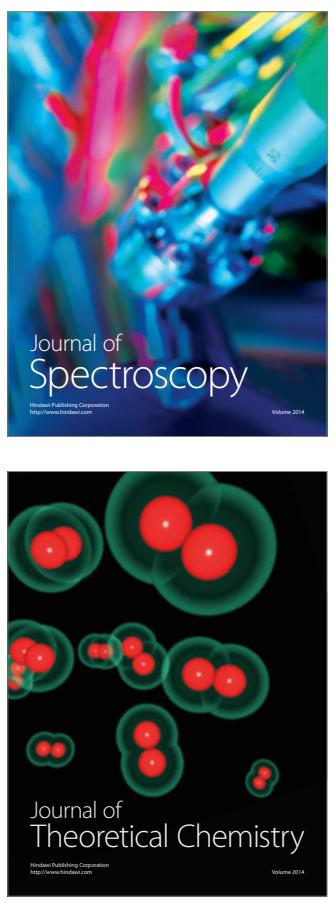
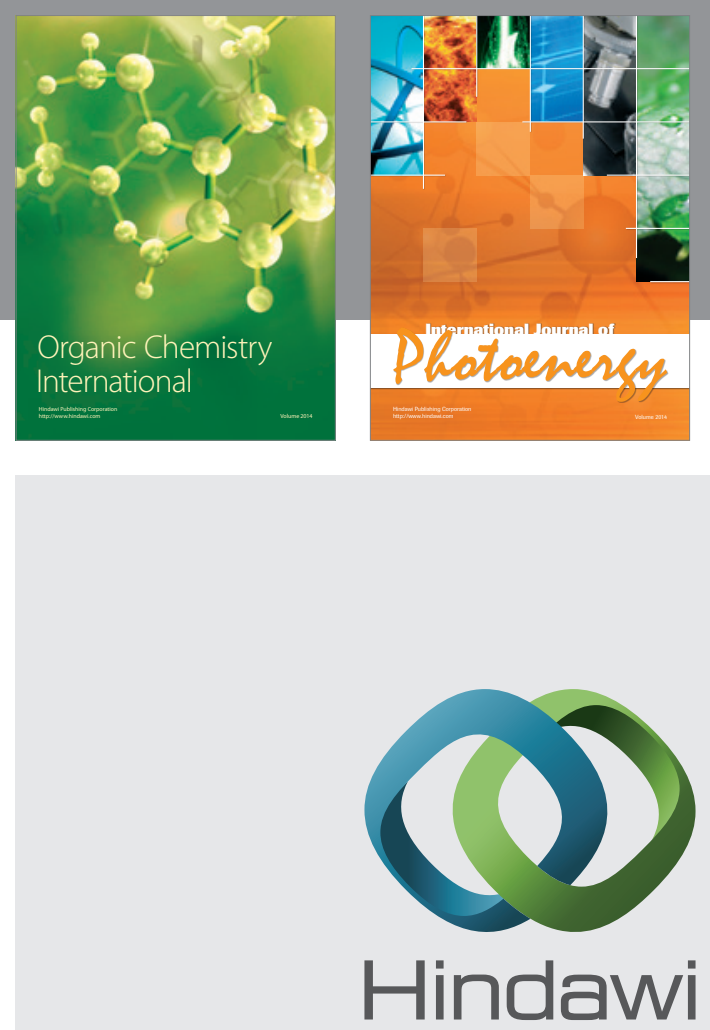

Submit your manuscripts at

http://www.hindawi.com
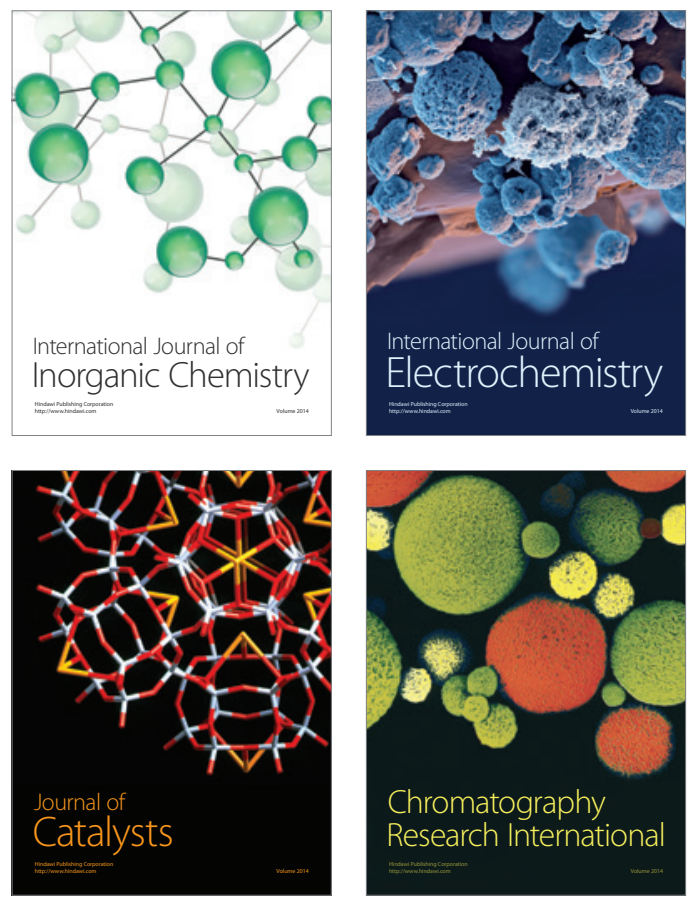
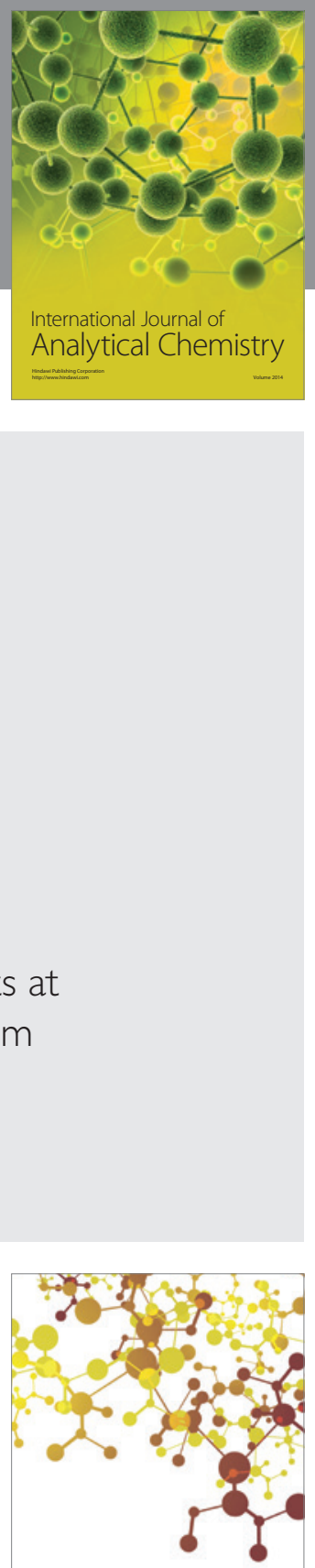

Journal of

Applied Chemistry
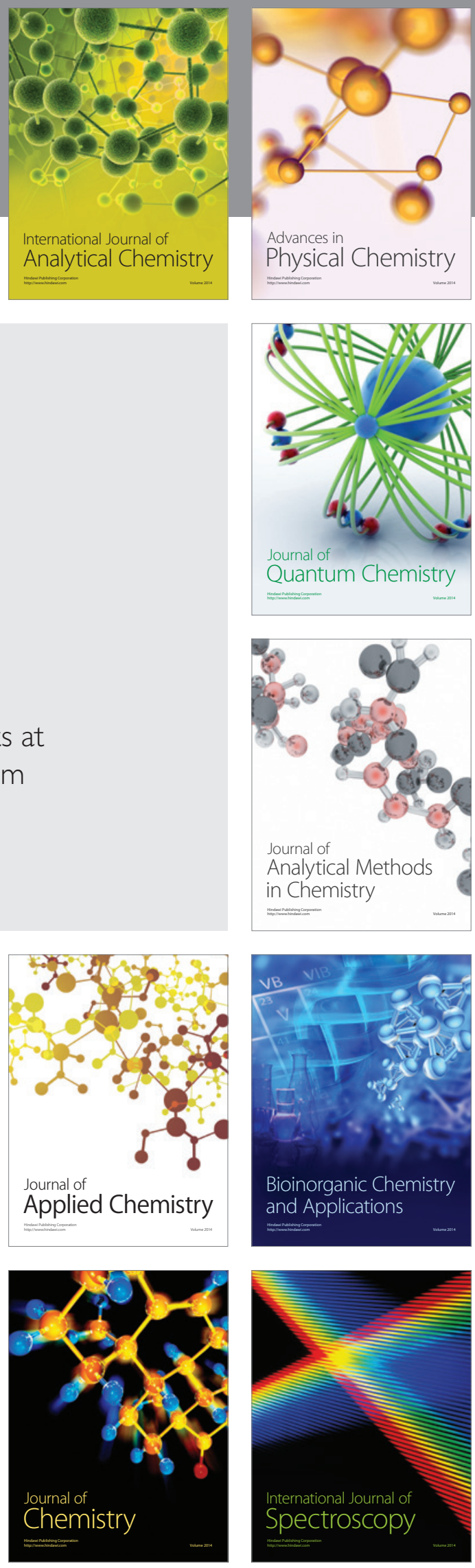